\title{
Doyne honeycomb retinal dystrophy/ malattia leventinese induced by EFEMP1 mutation in a Chinese family
}

\author{
Kaiyan Zhang, Xuyang Sun", Yingying Chen, Qionglei Zhong, Lin Lin, Yuan Gao and Fanlin Hong
}

\begin{abstract}
Background: Doyne honeycomb retinal dystrophy (DHRD)/malattia leventinese (ML) is a rare allelic condition with massive drusen in the posterior fundus caused by EFEMP1 gene mutation. Patients showed decreased vision when the lesion affected the macular area. At present, the treatment efficiency is not satisfactory.

Case presentation: In this study, we presented a family with DHRD/ML disease and analyzed the pathological and genetic information. A 28-year-old female patient presented to our department due to impaired visual acuity for 10 years especially in the right eye with deterioration for 5 months. Gene sequencing was performed by MyGenostics (Peking, China). Gene sequencing results revealed heterozygous mutations in EFEMP1 gene, which were consistent with the DHRD/ ML. Single heterozygous mutation (c.1033C > T) was observed in each of the three blood samples. This missense mutation triggered p.R345W.

Conclusions: DHRD/ML is a rare disease associated with EFEMP1 gene mutation. Up to now, we are not sure whether these lesions are associated with the onset of DHRD/ML. In future, we hope to find out the exact relationship between them.
\end{abstract}

Keywords: Doyne honeycomb retinal dystrophy, Malattia leventinese, Drusen, Visual acuity

\section{Background}

Doyne honeycomb retinal dystrophy (DHRD)/Malattia leventinese $(\mathrm{ML})$ is caused by a single mutation in EFEMP1 that encodes the epidermal growth factor-containing fibrillin-like extracellular matrix protein 1 [1]. In its early stages, the disease appears as massive drusens, while the visual acuity of the patients would decrease with the lesion progress [2]. To date, laser therapy and anti-VEGF therapy have been utilized for the treatment, but the treatment is still a challenge as there is no effective way to correct the gene mutation of such condition [3]. In this study, we reported a family with DHRD/ML disease that presented different features with the former reports. It contributed to the diversity of DHRD/ML.

\section{Case presentation}

A 28-year-old female patient presented to our department due to blurry visual acuity for 10 years especially in the right eye with deterioration for 5 months. The best corrected visual acuity (BCVA) in the right and left eyes was 5.0 and 5.1 (logmar visual acuity chart), respectively. The intraocular pressure (IOP) in the right and left eyes was 17 $\mathrm{mmHg}$ and $18 \mathrm{mmHg}$, respectively. No abnormalities were observed in the anterior segment of both eyes. Fundus examination showed that the optic disc was normal, while the remarkable diffuse pinpoint or drusen-like speckle yellow white lesions affected the posterior fundus, with varying degrees of retina/retinal pigment epithelium (RPE)/ choroid atrophy around the disc. The fovea light reflex was not clear (Figs. 1 and 2). Optical coherence tomography

* Correspondence: 372391802@qq.com

Department of Ophthalmology, Hainan General Hospital, Haikou 570102,

China

(c) The Author(s). 2018 Open Access This article is distributed under the terms of the Creative Commons Attribution 4.0 International License (http://creativecommons.org/licenses/by/4.0/), which permits unrestricted use, distribution, and 

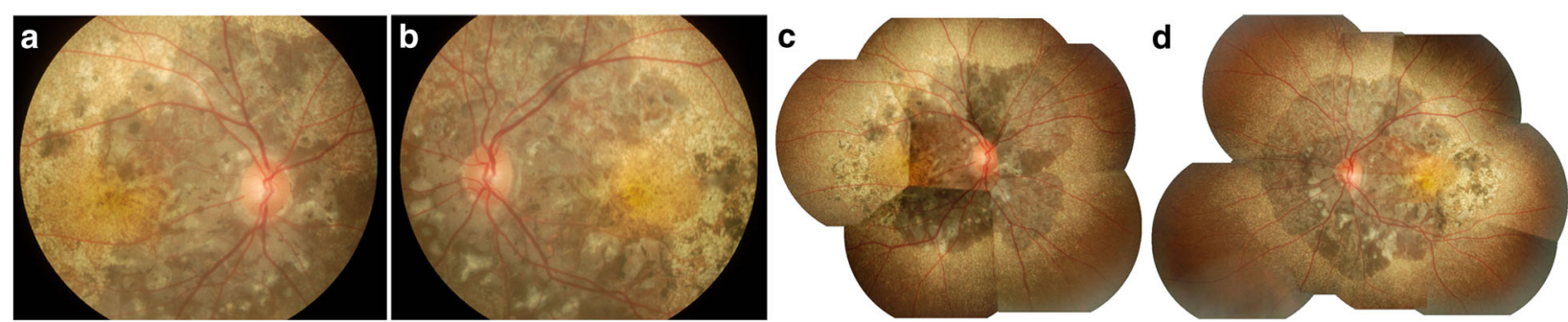

Fig. 1 Fundus color photography. RPE/choroid atrophy was noticed in the posterior fundus around the disc, with diffuse pinpoint or speckle yellowish white lesions involving the peripheral area reached to the equator (a: right eye; $\mathbf{b}$ : left eye). Color photo puzzle showed relatively normal findings in peripheral fundus (c: right eye; $\mathbf{d}$ : left eye)

(OCT) scan showed extensive hyperreflective thickening beneath the retinal pigment epithelium (RPE, Fig. 3). Fundus fluorescein angiography (FFA) and indocyanine green angiography (ICGA) assumed that RPE/choroidal disorder was featured by "honeycomb" appearance (Fig. 4). Visual field showed defect in the temporal sides (Fig. 5). Electrophysiological examination findings (e.g. ERG, EOG, and VEP) were normal.

Her 22-year-old brother showed BCVA of 5.0 (logmar visual acuity chart) in both eyes. Fundus examination showed diffuse pinpoint yellow white deposits throughout the macular and peripapillar area with honeycomblike pigmentary changes around the disc (Fig. 6a and b). OCT scan showed a hyperreflective thickening beneath the pigmentary epithelium accompanied by wavy uplift (Fig. 7a and b).

Her 54-year-old mother complained of poor visual acuity for at least 20 years, especially at nighttime. The BCVA of the right eye was $\mathrm{FC} / 10 \mathrm{~cm}$, and the left eye was 4.0 (logmar visual acuity chart). She had corneal opacity in both eyes (Fig. 8a and b), and the fundus could not be observed clearly. Corneal scan of OCT showed granular cloudiness, and corneal endothelium detachment in the peripheral part (Fig. 8c and d). Color Doppler ultrasonography of eyeball showed thickening in the posterior wall of both eyeballs.

Her father showed no history of ocular diseases. He would not come to our hospital for the ocular examinations due to personal reasons.

After signing the informed consents, venous blood was collected from the female patient, her mother and her brother, respectively. Gene sequencing was performed by MyGenostics (Peking, China). Gene sequencing revealed heterozygous mutations in EFEMP1 gene, which was consistent with the DHRD/ML. The study protocols were approved by the Ethical Committee of Hainan General Hospital. For the gene sequencing, single heterozygous mutation $(c .1033 C>T)$ was observed in each of the three blood samples. This missense mutation triggered p.R345W (Fig. 9).
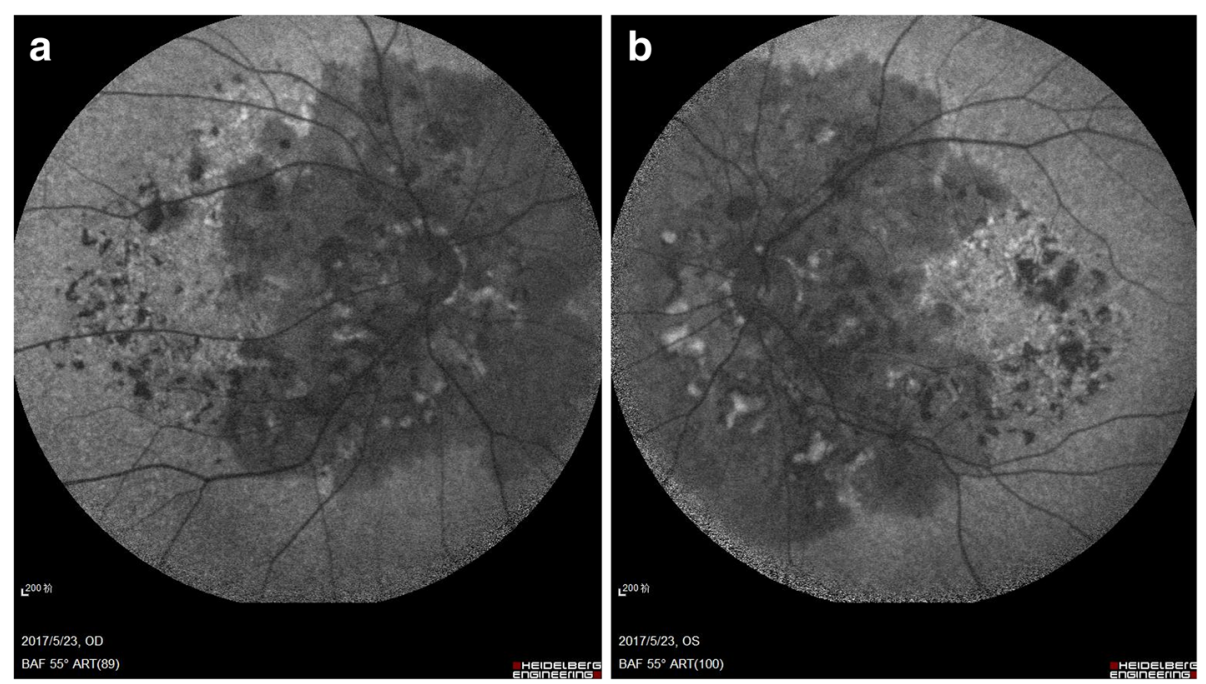

Fig. 2 Fundus autofluorescence. Hypoautofluorescence was observed in the posterior fundus around the disc, which was corresponded to the surrounding black lesions of optic in fundus color photography (a: right eye; $\mathbf{b}$ : left eye) 

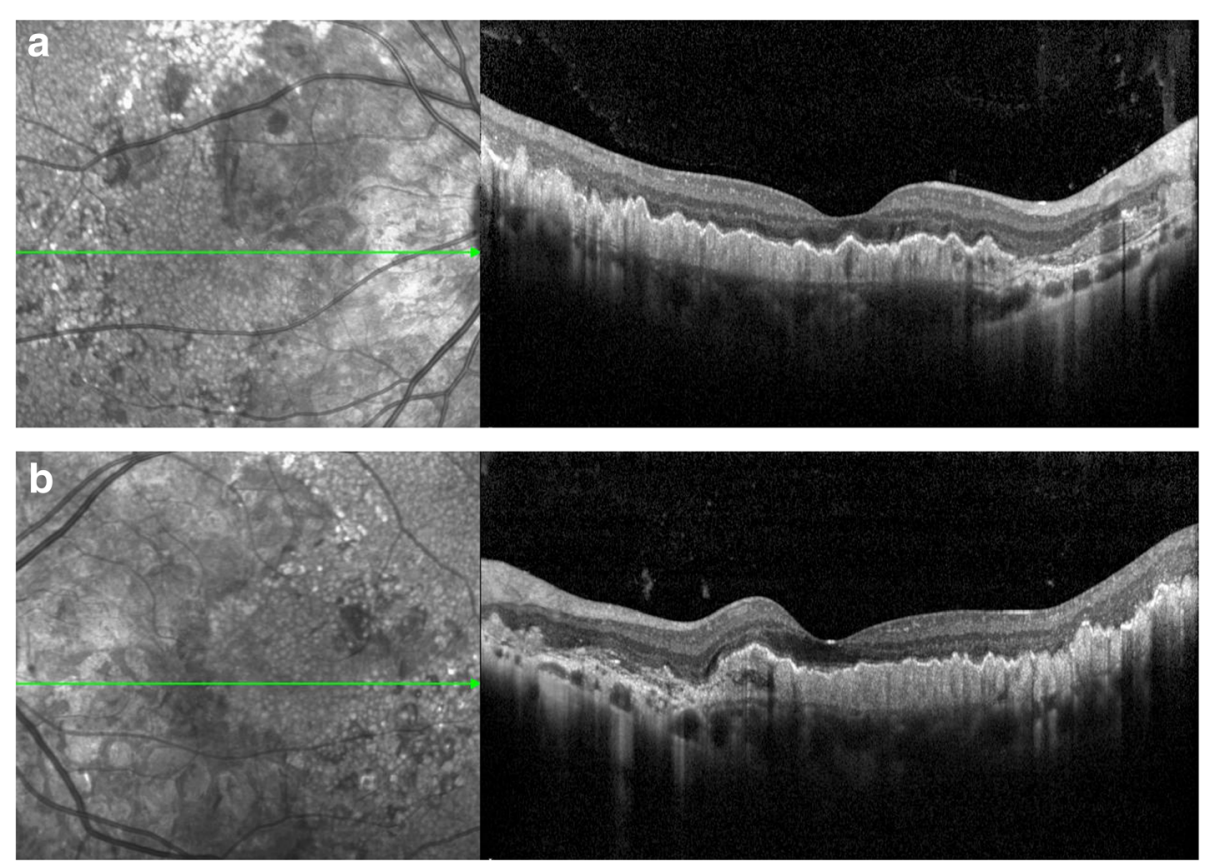

Fig. 3 OCT scanning. A hyperreflective thickening was noticed beneath the RPE accompanied by wavy uplift (a: right eye; b:left eye)
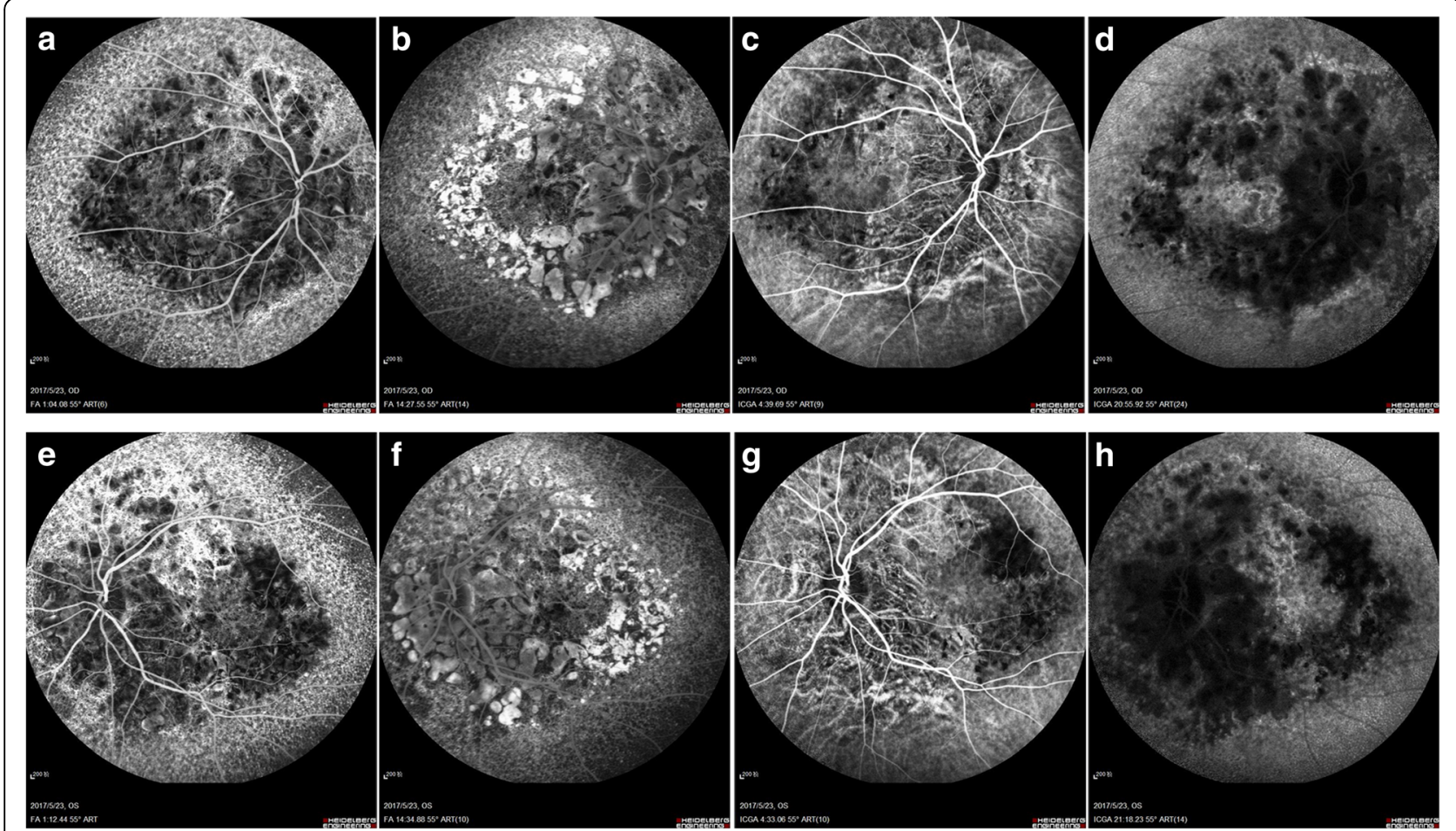

Fig. 4 FFA and ICGA. In the early phase of FFA, the background fluorescence was observed around the disc decreased with choroidal vascular exposed, and diffuse pinpoint hyperfluorescent leakage was noticed in the peripheral parts reached to the equator (a: right eye; e: left eye). In the late phase of FFA, the hypofluorescence around the disc grew to hyperfluorescence formed to be "honeycomb" appearance in the posterior pole (b: right eye; f: left eye). In the early phase of ICGA, choroidal vascular exposed in the posterior pole around the disc (c: right eye; g: left eye). In the late phase of ICGA, massive hypofluorescence of choroidal was noticed in the posterior pole around the disc, while hyperfluorescence was observed in the peripheral parts reached to the equator (d:-right eye; $\mathbf{h}$ : left eye) 


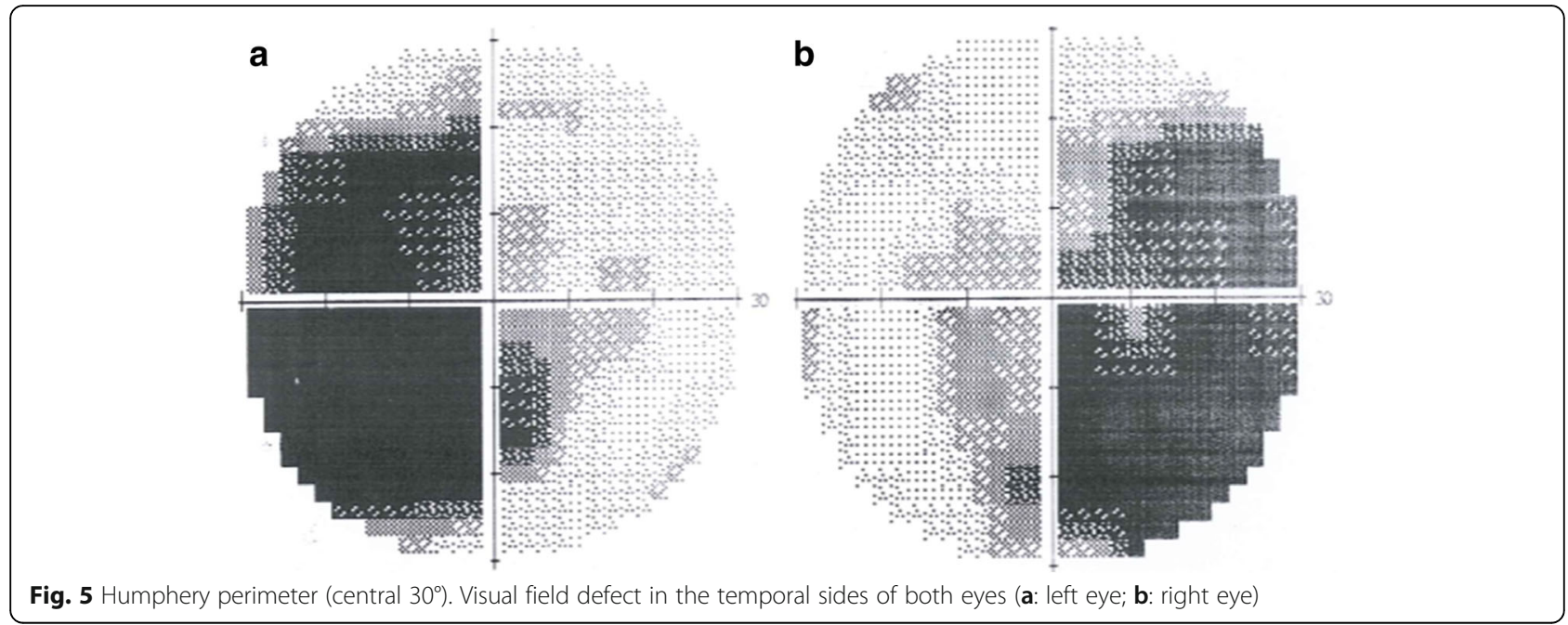

\section{Discussion}

DHRD was initially reported in 1899 by Doyne, which was featured by closely-grouped white spots involving the disc-macular area in a pattern termed honeycomb [4]. Also, it is manifested as diffuse retina white spots. To our best knowledge, ML was initially described initially in inhabitants or descendants in the Leventine valley of Tessin Canton in Southern Switzerland [5]. In a previous study, Haimovici et al. [6] summarized the typical onset age and features of such condition, which was featured by drusen-like deposits in the macula and around the optic nerve that were usually apparent by the age of 20. Moreover, most of the patients were asymptomatic, and then the patients developed more numerous and larger drusen. In this literature, the authors also mentioned that the earliest visual symptoms included dyschromatopsia, metamorphopsia, or relative scotomas at the age of $30-40$ yrs. Central visual acuity usually showed deterioration at the age of $40-50 \mathrm{yrs}$., however, it may occur at 30 or be delayed until 60 yrs [6]. In the later stages, the majority of patients showed loss of central vision and absolute scotomas, which was associated with the development of extensive pigmentary changes and geographic atrophy (GA) or choroidal neovascularization $(\mathrm{CNV})$ in the region of the confluent macular drusen [6].

Recently, DHRD and ML are considered as the same disease because of similar clinical symptoms. In a previous study, Stone et al. revealed a single non-conservative mutation (Arg345Trp) in EFEMP1 gene that was associated with the pathogenesis of ML and DHRD [1]. EFEMP1 gene, localized on chromosome 2p16-21, encodes an extracellular matrix protein expressed in the retina, RPE and choroid [7]. Besides, it showed homology among the protein members [8]. EFEM$P 1$-encoded protein may interact with the other extracellular matrix proteins such as connexin, collagen, fibronectin, and laminin, which contributed to the formation of drusen [1]. The clinical symptoms and pathogenesis of DHRD/ML are similar with that of age-related macular degeneration (AMD), which is featured by soft drusen, external RPE structure loss, RPE
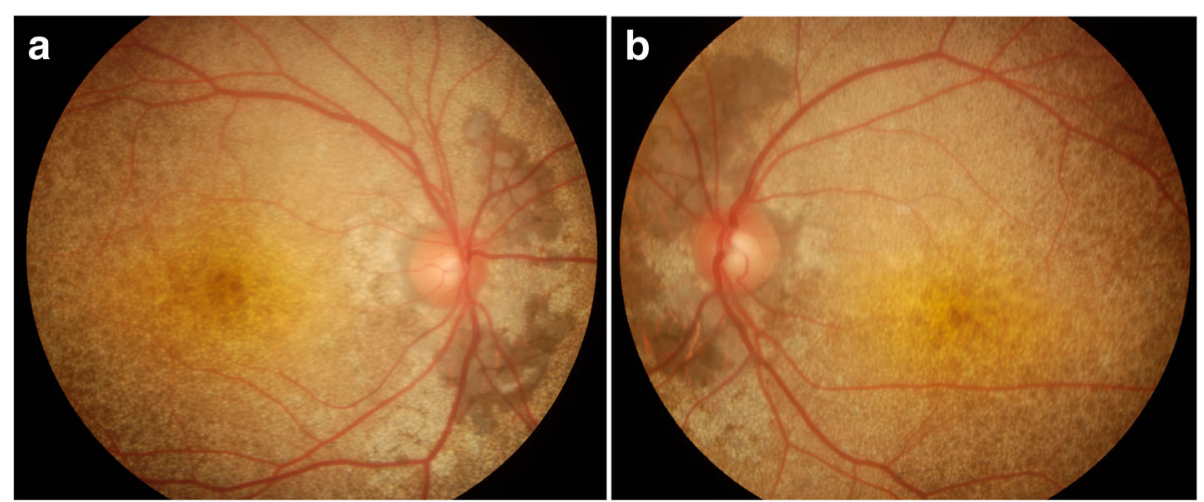

Fig. 6 Fundus color photography of the brother. RPE/choroid atrophy was noticed in the posterior fundus around the disc, with diffuse pinpoint or speckle yellowish white lesions involving the peripheral area reached to the equator(a: right eye; $\mathbf{b}$ : left eye) 

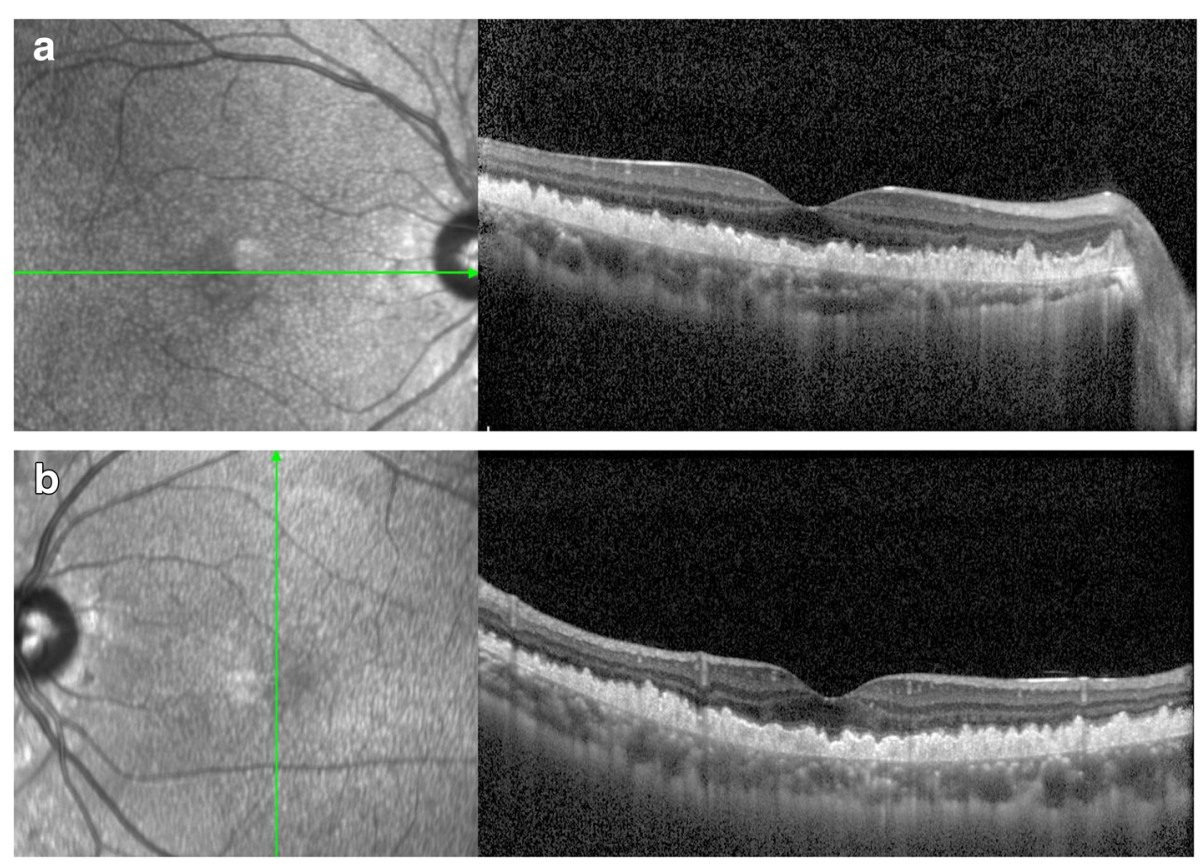

Fig. 7 OCT scanning of the brother. A hyperreflective thickening was noticed beneath the RPE (a: right eye; b: left eye)

vacuolation and atrophy, as well as the final neovascularization at the age of less than 40 yrs. [9]. However, they are indeed different diseases. The mutation (Arg345Trp) of EFEMP1 was reported to show no association with the drusen related lesions such as AMD [10]. Meanwhile, no Arg345Trp mutation was identified in the cases with dispersed or familial AMD [11]. Thus far, the Arg345Trp mutation is the only mutation identified in the coding or adjacent intronic regions of EFEMP1 gene in familial or sporadic early onset drusen. This suggests that the Arg345Trp mutation is responsible for producing a specific drusen
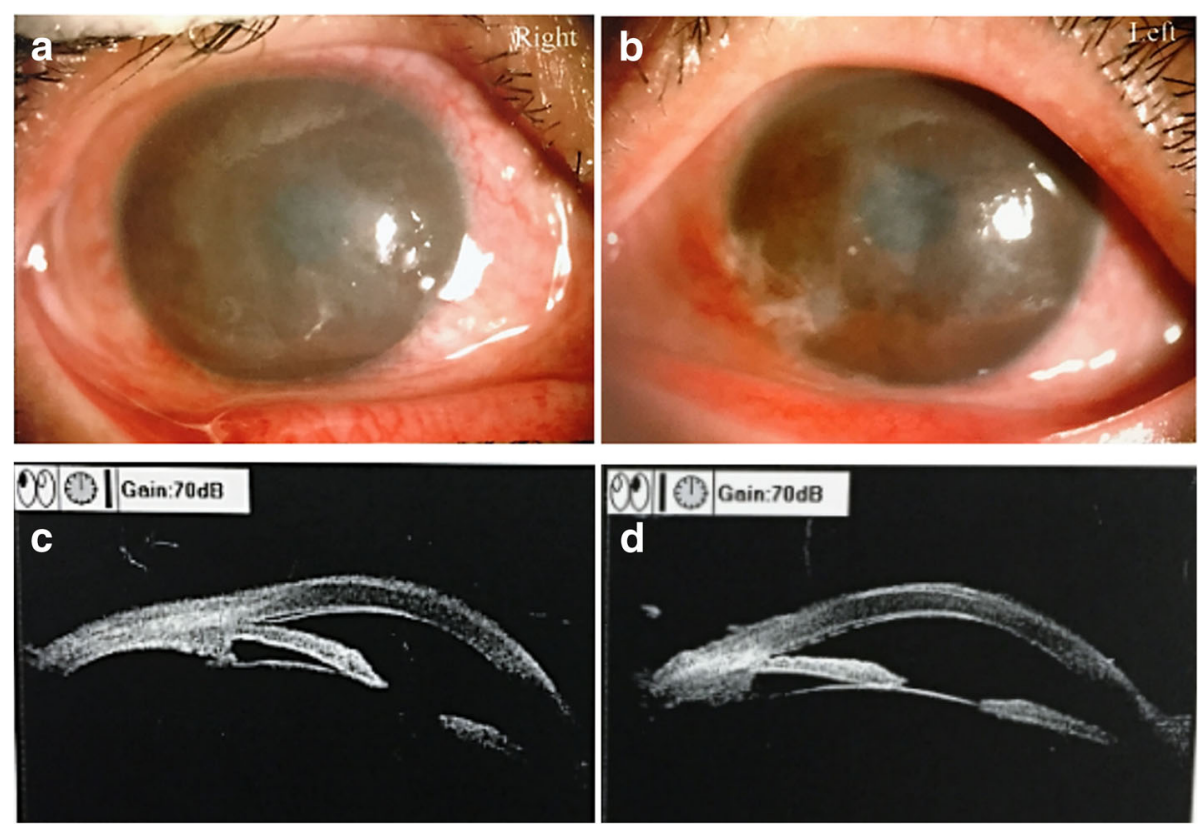

Fig. 8 Corneal photography and OCT scan of the mother. Corneal opacity was noticed, and was uneven (a: right eye; b: left eye). The corneal epithelium was thicken and coarse, and detachment was noticed in the corneal endothelium at the 12 o'clock position(c: right eye; $\mathbf{d}$ : left eye) 


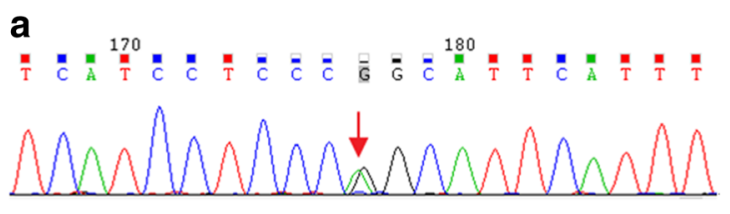

b
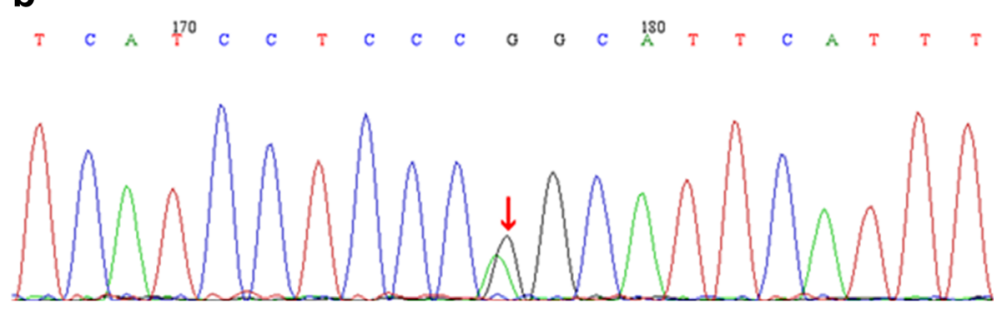

C
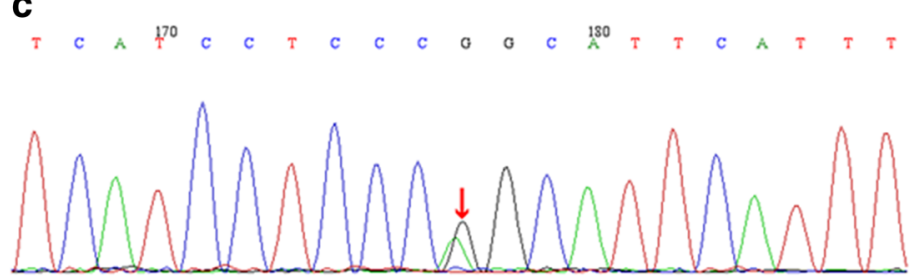

d
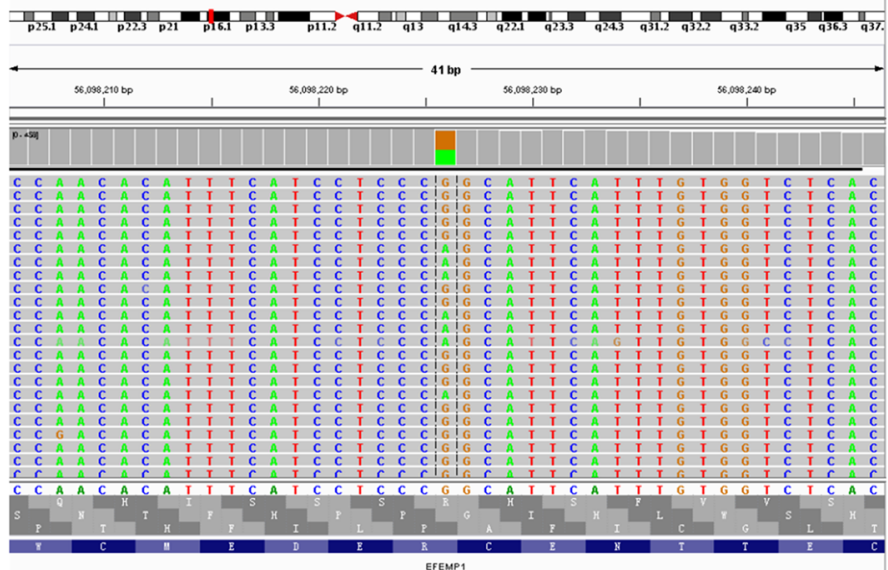

Fig. 9 Gene sequencing results. The first generation sequencing results indicated mutation of EFEMP1 (c.1033C > T, p.R345 W) in the patient (a), his brother (b) and mother (c). The second generation sequencing results for the EFEMP1 gene (d). Sequencing findings for the patient

phenotype (drusen around the optic nerve head in DHRD and radial drusen in ML) [12]. In a previous study aimed to distinguish DHRD apart from ML, DHRD patients were considered to present comby drusen in the posterior fundus, while smaller discrete drusen radially distributed around the macula in ML patients [13].

To date, there were few reports of ML/DHRD. In China mainland, there was only one case report of R345W mutation in EFEMP1 caused ML/DHRD in a family [14]. In that report, 6 members of one family at the age of 37-61 yrs., and the proband was 43 yrs., all of whom showed drusen distributed in the fundus, 2 had
RPE disorders and CNV. In this study, we identified a heterozygous mutation of EFEMP1 in a family with a 28-yrs sister of proband, a 22-yrs brother, and their mother. Our clinical findings were not similar with previously reported cases, despite some similarities [11-15]. Firstly, the young proband in this study presented clustered drusen reaching the equator of fundus with no $\mathrm{CNV}$ in the macula, while all previous cases showed drusen only localized in the macular region not exceeding the vascular arch. Secondly, besides remarkable drusen, there were large dark gray lesions originated from $\mathrm{RPE} /$ choroid atrophy in the posterior pole around the disc. No such feature was reported in the previous 
literature, even a few cases presented pigment proliferation in the macula [11-14]. Thirdly, the vision of the patient and her brother was not significantly impaired despite of the wide damages in the fundus. Some reports $[4,12]$ showed declined vision if there were densely large drusen in the macular area, which may deteriorate when combing with CNV and RPE disorder. However, in the 5-yr follow-up [16] of a Japanese female patient with $\mathrm{DHRD} / \mathrm{ML}$, one eye of BCVA remained normal in spite of aggravation of drusen and pigmentation in the macula, and the other eye showed vision loss due to CNV of macula. Furthermore, the brother present remarkable diffused drusen, while milder RPE /choroid damages of honeycomb-like appearance were noticed in the posterior pole around the disc. Nevertheless, it showed no clinical symptoms at present. The sister presented visual field defects corresponding to the peripapillary RPE/ choroid damages. Thus, we deduced the pinpoint, yellowish, white drusen might represent the early stage of this disease, which then fused to patchy drusen. However, the dark gray lesions of RPE/choroid atrophy around the optic disc might imply progress of the disease with following vision loss. Multifocal ERG, OCT or FFA/ICGA examinations and visual field examinations may contribute to long-term follow-up [16-18].

For the treatment, Lenassi et al. [19] reported that low-energy laser treatment was safe and might be effective for treating autosomal dominant drusen induced by EFEMP1 mutation. In 11 patients with autosomal dominant drusen and confirmed with disease-causing EFEMP1 mutation, the eyes with poor vision were treated with Argon green laser. The untreated eyes lost an average of 0.8 letters, whereas, the treated eyes gained an average of 4.9 letters. The average thickness of the drusen in the untreated eyes showed increase, while no changes were noticed in the treated eyes. Meanwhile, Sohn et al. [20] showed that $\mathrm{CNV}$ in DHRD was sensitive to treatment with intravitreal bevacizumab which was featured by absorption of subretinal fluid and improvement of visual acuity in two cases.

In this study, the patient and her brother had almost normal central vision, which might the associated with the fact that the lesion did not involve the fovea. We implied that there would be a vision loss when the RPE/choroid atrophy invaded the macula. Anyway, long-term follow up was still required, and immediate treatment was recommended in cases of deterioration of drusen or $\mathrm{CNV}$ formation, in order to keep the vision. On the other hand, her mother showed long-term corneal opacity with granular cloudiness. Up to now, we are not sure whether these lesions are associated with the DHRD/ML. In the future, we hope to find out the exact relations between them.

\section{Abbreviations}

AMD: Age-related macular degeneration; BCVA: Best corrected visual acuity; CNV: Choroidal neovascularization; DHRD: Doyne honeycomb retinal dystroph; FFA: Fundus fluorescein angiography; GA: Geographic atrophy; ICGA: Indocyanine green angiography; IOP: Intraocular pressure; ML: Malattia leventinese; OCT: Optical coherence tomography; RPE: Retinal pigment epithelium

\section{Acknowledgements}

Not applicable.

\section{Funding}

This study was granted by the Hainan Medical and Health Research Project (No. 14A200031) and Hainan Provincial Social Development Special Fund for Science and Technology Grant (No. SF201412).

\section{Availability of data and materials}

The datasets used and/or analyzed during the current study are available from the corresponding author on reasonable request.

\section{Authors' contributions}

ZKY wrote the manuscript; SXY revised the manuscript and finally approved the version to be published; CYY, ZQL, LL did the data analysis; GY, HFL did the data collection. All authors have read and approved the manuscript, and ensure that this is the case.

Ethics approval and consent to participate

The study protocols were approved by the Ethical Committee of Hainan General Hospital.

\section{Consent for publication}

Written informed consent for the publication has been obtained from the patient. Consent for publication was also obtained from the patient's family.

\section{Competing interests}

The authors declare that they have no competing interests.

\section{Publisher's Note}

Springer Nature remains neutral with regard to jurisdictional claims in published maps and institutional affiliations.

Received: 16 May 2018 Accepted: 30 November 2018

Published online: 12 December 2018

\section{References}

1. Stone EM, Lotery AJ, Munier FL, Heon E, Piguet B, Guymer RH, Vandenburgh K, Cousin P, Nishimura D, Swiderski RE, et al. A single EFEMP1 mutation associated with both Malattia Leventinese and Doyne honeycomb retinal dystrophy. Nat Genet. 1999;22(2):199-202.

2. Gerth C, Zawadzki RJ, Werner JS, Heon E. Retinal microstructure in patients with EFEMP1 retinal dystrophy evaluated by Fourier domain OCT. Eye (London, England). 2009;23(2):480-3.

3. Marmorstein LY, Munier FL, Arsenijevic Y, Schorderet DF, McLaughlin PJ, Chung D, Traboulsi E, Marmorstein AD. Aberrant accumulation of EFEMP1 underlies drusen formation in Malattia Leventinese and age-related macular degeneration. Proc Natl Acad Sci U S A. 2002;99(20):13067-72.

4. Pearce WG. Doyne's honeycomb retinal degeneration. Clinical and genetic features. Br J Ophthalmol. 1968;52(2):73-8.

5. Vogt A. Handbuch der gesammten Augenheilkunde. Untersuchungsmethoden. 3rd ed. Berlin: Springer Verlag; 1925.

6. Haimovici R, Wroblewski J, Piguet B, Fitzke FW, Holder GE, Arden GB, Bird AC. Symptomatic abnormalities of dark adaptation in patients with EFEMP1 retinal dystrophy (Malattia Leventinese/Doyne honeycomb retinal dystrophy). Eye (London, England). 2002;16(1):7-15.

7. Heon E, Piguet B, Munier F, Sneed SR, Morgan CM, Forni S, Pescia G, Schorderet D, Taylor CM, Streb LM, et al. Linkage of autosomal dominant radial drusen (malattia leventinese) to chromosome 2p16-21. Arch Ophthalmol (Chicago, III : 1960). 1996:114(2):193-8.

8. Tran H, Mattei M, Godyna S, et al. Human fibulin-1D: molecular cloning, expression and similarities with \$1-5 protein, a new member of the fibulin gene family. Matrix Biol. 1997;15(7):479-93. 
9. Hulleman JD, Kaushal S, Balch WE, Kelly JW. Compromised mutant EFEMP1 secretion associated with macular dystrophy remedied by proteostasis network alteration. Mol Biol Cell. 2011;22(24):4765-75.

10. Hulleman JD. Malattia Leventinese/Doyne honeycomb retinal dystrophy: similarities to age-related macular degeneration and potential therapies. Adv Exp Med Biol. 2016;854:153-8.

11. Guymer RH, McNeil R, Cain M, Tomlin B, Allen PJ, Dip CL, Baird PN. Analysis of the Arg345Trp disease-associated allele of the EFEMP1 gene in individuals with early onset drusen or familial age-related macular degeneration. Clin Exp Ophthalmol. 2002;30(6):419-23.

12. Narendran N, Guymer RH, Cain M, Baird PN. Analysis of the EFEMP1 gene in individuals and families with early onset drusen. Eye (London, England). 2005;19(1):11-5.

13. Piguet B, Haimovici R, Bird AC. Dominantly inherited drusen represent more than one disorder: a historical review. Eye (London, England). 1995:9(Pt 1):34-41.

14. Zhang T, Xie X, Cao G, Jiang H, Wu S, Su Z, Zhang K, Lu F. Malattia leventinese/ Doyne honeycomb retinal dystrophy in a chinese family with mutation of the EFEMP1 gene. Retina (Philadelphia, Pa). 2014;34(12):2462-71.

15. Querques G, Guigui B, Leveziel N, Querques L, Bandello F, Souied EH. Multimodal morphological and functional characterization of Malattia Leventinese. Graefe's Arch Clin Exp Ophthalmol. 2013;251(3):705-14.

16. Takeuchi T, Hayashi T, Bedell M, Zhang K, Yamada H, Tsuneoka H. A novel haplotype with the R345W mutation in the EFEMP1 gene associated with autosomal dominant drusen in a Japanese family. Invest Ophthalmol Vis Sci. 2010;51(3):1643-50.

17. Souied EH, Leveziel N, Querques G, Darmon J, Coscas G, Soubrane G. Indocyanine green angiography features of Malattia leventinese. $\mathrm{Br} J$ Ophthalmol. 2006;90(3):296-300.

18. Souied EH, Leveziel N, Letien V, Darmon J, Coscas G, Soubrane G. Optical coherent tomography features of malattia leventinese. Am J Ophthalmol. 2006;141 (2):404-7.

19. Lenassi E, Troeger E, Wilke R, Tufail A, Hawlina M, Jeffery G, Webster AR. Laser clearance of drusen deposit in patients with autosomal dominant drusen (p.Arg345Trp in EFEMP1). Am J Ophthalmol. 2013;155(1):190-8.

20. Sohn EH, Patel PJ, MacLaren RE, Adatia FA, Pal B, Webster AR, Tufail A. Responsiveness of choroidal neovascular membranes in patients with R345W mutation in fibulin 3 (Doyne honeycomb retinal dystrophy) to antivascular endothelial growth factor therapy. Arch Ophthalmol (Chicago, III : 1960). 2011:129(12):1626-8

Ready to submit your research? Choose BMC and benefit from:

- fast, convenient online submission

- thorough peer review by experienced researchers in your field

- rapid publication on acceptance

- support for research data, including large and complex data types

- gold Open Access which fosters wider collaboration and increased citations

- maximum visibility for your research: over $100 \mathrm{M}$ website views per year

At $\mathrm{BMC}$, research is always in progress.

Learn more biomedcentral.com/submissions 